\title{
Underground Nuclear Astrophysics in China
}

\author{
Liu WeiPing ${ }^{1}$ for JUNA collaboration \\ ${ }^{1}$ China Institute of Atomic Energy, P. O. Box 275(1), Beijing 102413, China
}

\begin{abstract}
Underground Nuclear Astrophysics in China (JUNA) will take the advantage of the ultra-low background in Jinping underground lab. High current accelerator with an ECR source and detectors will be set up. We plan to study directly a number of nuclear reactions important to hydrostatic stellar evolution at their relevant stellar energies, such as ${ }^{25} \mathrm{Mg}(\mathrm{p}, \gamma)^{26} \mathrm{Al}$, ${ }^{19} \mathrm{~F}(\mathrm{p}, \alpha){ }^{16} \mathrm{O},{ }^{13} \mathrm{C}(\alpha, \mathrm{n}){ }^{16} \mathrm{O}$ and ${ }^{12} \mathrm{C}(\alpha, \gamma){ }^{16} \mathrm{O}$.
\end{abstract}

Keywords. direct measurement, underground laboratory, Gamow window, JUNA

\section{Underground physics}

Direct measurement of the cross sections for the key nuclear reactions crucial to hydrostatic stellar evolution within Gamow window is important for solving key scientific questions in nuclear astrophysics (Iliadis 2007). The direct measurement of astrophysical reaction rates on stable nuclei require high-intensity beams and extremely low background, which represents the major challenge at the frontiers of nuclear astrophysics. The largest challenge is the small cross section amid with large natural background. With the ultra-low background in deep underground environment, direct measurement of these key reactions in underground lab becomes a frontier in the field of experimental nuclear astrophysics. The first underground based low-energy accelerator facility, LUNA (Formicola et al. 2003; Costantini et al. 2009) at Gran Sasso underground laboratory, has successfully demonstrated the feasibility of meeting these challenges.

China JinPing underground Laboratory (CJPL) was established from a constructing hydro-power plant in the Jinping mountain, Sichuan, China (Chen 2010; Cheng et al. 2011). The facility is located near the middle of traffic tunnel. The facility is shielded by $2400 \mathrm{~m}$ of mainly marble overburden, with radioactively quiet rock. Its ultra-low cosmic ray background, which is about 2 orders of magnitude lower than that in Gran Sasso, makes it into an ideal environment for low background experiment. CJPL phase I (CJPLI) now houses CDEX (Zhao et al. 2013) and PandaX dark matter experiments. CJPL phase II (Normile 2014) (CJPL-II) is expected to be available by the beginning of 2016 for much larger scale underground experiments $\left(120,000 \mathrm{~m}^{3}\right.$ volume). JUNA will be one of its major research programs in CJPL-II.

\section{Nuclear reactions}

\section{1. $\left.{ }^{12} C(\alpha, \gamma)\right)^{16} O$ reaction}

The ${ }^{12} \mathrm{C}(\alpha, \gamma){ }^{16} \mathrm{O}$ reaction is quoted as the holy grail in nuclear astrophysics (Rolfs \& Rodney 1988). The uncertainty of this reaction affects not only the nucleosynthesis of elements up to iron, but also the evolution of the massive stars and their final fate (black hole, neutron star). The cross section of this reaction has to be known within an uncertainty less than $10 \%$ at helium burning temperatures $\left(\mathrm{T}_{9}=0.2\right)$, corresponding to a Gamow window around $\mathrm{E}_{c . m} .=300 \mathrm{keV}$. It is extremely difficult to determine the reaction cross section (about $10^{-17}$ barn) at this energy (Buchmann 2005). Current technology 
can only achieve $10^{-14}$ barn cross section level. A direct measurement at $\mathrm{E}_{c . m}=600$ $\mathrm{keV}$ near the Gamow window will be done in JUNA with high intensity ion beam of the experimental platform to provide better constraints for extrapolating models (Liu 2014).

For total cross section measurement at $\mathrm{E}_{c . m}=600 \mathrm{keV}$, with the results of angular distribution measurement at $\mathrm{E}_{c . m} .=600 \mathrm{keV}$, we will optimize the experiment condition, including: 1) optimizing the beam transmission on the basis of the beam-optics calculation, adjusting the setup of shields to suppress the background coming from the beam, 2) confirming the origin of ${ }^{13} \mathrm{C}$ and improving the implantation condition of ${ }^{12} \mathrm{C}$ implantation target to reduce the disturbance of ${ }^{13} \mathrm{C}$. The BGO detection array placed around the target chamber can significantly increase the detection efficiency (absolute efficiency $75 \%$ at $\mathrm{E}_{\gamma}=6 \mathrm{MeV}$ ) of $\gamma$-rays. With the improvement above, an accurate total cross section will be obtained.

For total cross section test measurement at $\mathrm{E}_{c . m .}=380 \mathrm{keV}$, we will use ${ }^{4} \mathrm{He}^{2+}$ beam with an intensity of $2.5 \mathrm{emA}$ and an energy of $507 \mathrm{keV}\left(\mathrm{E}_{c . m}=380 \mathrm{keV}\right)$ and the high-efficiency BGO detection array. A direct measurement of the total cross section of ${ }^{12} \mathrm{C}(\alpha, \gamma){ }^{16} \mathrm{O}$ in the energy region of near Gamow window will be tested.

\section{2. ${ }^{13} C(\alpha, n)^{16} O$ reaction}

The ${ }^{13} \mathrm{C}(\alpha, \mathrm{n}){ }^{16} \mathrm{O}$ reaction is the key neutron source reaction for the stellar s-process nucleosynthesis. Due to the existence of sub-threshold resonances, there is a rather large uncertainty $(30 \%)$ in this important reaction rate which limits our understanding to the nucleosynthesis of heavy elements. We plan to study directly this important reaction for the first time at energies down to $\mathrm{E}_{\text {c.m. }} \sim 0.2 \mathrm{MeV}$, within its relevant stellar energy range (Tang 2014).

We are designing a fast neutron detector consisting of $24{ }^{3} \mathrm{He}$ proportional counters and a liquid scintillator. The scintillator has a cylindrical shape with a length of $0.4 \mathrm{~m}$ and a diameter of $0.4 \mathrm{~m}$. The $24{ }^{3} \mathrm{He}$ counters are distributed in the two circles with radii of $0.1 \mathrm{~m}$ and $0.15 \mathrm{~m}$, respectively.

The energies of neutrons from the ${ }^{13} \mathrm{C}(\alpha, \mathrm{n}){ }^{16} \mathrm{O}$ reaction are in the range of 2 to 3 $\mathrm{MeV}$. The produced neutrons are firstly slowed down by the liquid scintillator. After their thermalization, some neutrons enter ${ }^{3} \mathrm{He}$ counters and are detected. With the coincidence between the fast signal from fast neutron slowing down inside the liquid scintillator and the delayed signal from the thermalized neutrons captured by the ${ }^{3} \mathrm{He}$ counters, we can effectively suppress the backgrounds in liquid scintillator and ${ }^{3} \mathrm{He}$ detectors. The detection efficiency after coincidence is estimated to be $20 \%$ for neutrons from the ${ }^{13} \mathrm{C}(\alpha, \mathrm{n}){ }^{16} \mathrm{O}$ reaction.

\section{3. ${ }^{25} \mathrm{Mg}(p, \gamma)^{26}$ Al reaction}

The ${ }^{25} \mathrm{Mg}(p, \gamma){ }^{26} \mathrm{Al}$ reaction is the main way to produce ${ }^{26} \mathrm{Al}$ in the Galaxy and its cross section is dominated by the capture process of the isolated resonances in ${ }^{26} \mathrm{Al}$. The temperature range of astrophysical interest is $\mathrm{T}=0.02-2 \mathrm{GK}$, so the levels between $50 \mathrm{keV}$ and $310 \mathrm{keV}$ are more important in the study of Galactic ${ }^{26} \mathrm{Al}$. Many experiments have been performed to study the ${ }^{25} \mathrm{Mg}(p, \gamma){ }^{26} \mathrm{Al}$ reaction since 1970 , but the experiment on the surface of earth can only reach to $190 \mathrm{keV}$ energy level due to the small cross section and large background effects of the cosmic rays. In 2012, the laboratory of underground nuclear astrophysics (LUNA) in Italy successfully measured the resonance strength at 92 $\mathrm{keV}$ with the help of high shielding conditions in the underground laboratory (Strieder et al. 2012; Straniero et al. 2013). However, the ${ }^{25} \mathrm{Mg}(p, \gamma){ }^{26} \mathrm{Al}$ cross section of $58 \mathrm{keV}$ resonant capture is inaccessible for direct measurement in the shielding conditions of LUNA experiments. The underground laboratory of Jinping in China is covered with the 
Table 1. Basic parameters of four reactions planned.

\begin{tabular}{l|cccccccc}
\hline reaction & beam & $\begin{array}{c}\text { intensity } \\
(\mathrm{emA})\end{array}$ & $\begin{array}{c}\text { c.m. energy } \\
(\mathrm{keV})\end{array}$ & cross section & target thickness efficiency & $\begin{array}{c}\text { CTS } \\
\text { (/day) }\end{array}$ & $\begin{array}{c}\text { BKD } \\
(/ \text { day })\end{array}$ \\
\hline${ }^{12} \mathrm{C}(\alpha, \gamma){ }^{16} \mathrm{O}$ & ${ }^{4} \mathrm{He}^{2+}$ & 2.5 & 380 & $10^{-13} \mathrm{mb}$ & $10^{18}$ atoms $/ \mathrm{cm}^{2}$ & 75 & 0.7 & 0.7 \\
${ }^{13} \mathrm{C}(\alpha, \mathrm{n})^{16} \mathrm{O}$ & ${ }^{4} \mathrm{He}^{1+}$ & 10 & 200 & $10^{-12} \mathrm{mb}$ & $10^{21}$ atoms $/ \mathrm{cm}^{2}$ & 20 & 7 & 1 \\
${ }^{25} \mathrm{Mg}(\mathrm{p}, \gamma)^{26} \mathrm{Al}$ & ${ }^{1} \mathrm{H}^{1+}$ & 10 & 58 & $\omega \gamma 2.1 \times 10^{-13} \mathrm{eV}$ & $0.6 \mu \mathrm{g} / \mathrm{cm}^{2}$ & 38 & 1.4 & 0.7 \\
${ }^{19} \mathrm{~F}\left(p, \alpha_{\gamma}\right)^{16} \mathrm{O}$ & ${ }^{1} \mathrm{H}^{1+}$ & 0.1 & 100 & $7.2 \times 10^{-9} \mathrm{mb}$ & $4 \mu \mathrm{g} / \mathrm{cm}^{2}$ & 75 & 27 & 0.7 \\
\hline
\end{tabular}

Table 2. Comparison of the goal for four reaction with current status.

\begin{tabular}{|c|c|c|c|c|c|c|}
\hline reaction & physics & $\begin{array}{c}\text { current } \\
\text { energy } \\
\text { limit }(\mathrm{keV})\end{array}$ & $\begin{array}{c}\text { precision } \\
(\%)\end{array}$ & ref. & $\begin{array}{c}\text { JUNA } \\
\text { energy } \\
\text { limit (keV) }\end{array}$ & $\begin{array}{c}\text { precision } \\
(\%)\end{array}$ \\
\hline${ }^{12} \mathrm{C}(\alpha, \gamma){ }^{16} \mathrm{O}$ & Massive star & 890 & 60 & Hammer et al. (2005) & 380 & test \\
\hline${ }^{13} \mathrm{C}(\alpha, \mathrm{n}){ }^{16} \mathrm{O}$ & Heavy ion synthesis & 279 & 60 & Drotleff et al. (1993) & 200 & 20 \\
\hline${ }^{25} \mathrm{Mg}(\mathrm{p}, \gamma){ }^{26} \mathrm{Al}$ & Galaxy ${ }^{26} \mathrm{Al}$ source & 92 & 20 & Strieder et al. (2012) & 58 & 15 \\
\hline${ }^{19} \mathrm{~F}\left(p, \alpha_{\gamma}\right){ }^{16} \mathrm{O}$ & F overabundance & 189 & 80 & Lombardo et al. (2015) & 100 & 10 \\
\hline
\end{tabular}

marble rock of 2400 meters. Benefiting from the ultra low background and the high beam intensity, we will be able to measure the $58 \mathrm{keV}$ resonance strength of ${ }^{25} \mathrm{Mg}(p, \gamma){ }^{26} \mathrm{Al}$ with the new designed $4 \pi$ BGO $\gamma$ detectors array.

\section{4. ${ }^{19} F(p, \alpha){ }^{16} O$ reaction}

The ${ }^{19} \mathrm{~F}(p, \alpha){ }^{16} \mathrm{O}$ reaction is considered to be an important reaction in the CNO cycle. Currently, the experimental cross sections of this reaction at Gamow energies are still incomplete, and the precision of its thermonuclear reaction rate does not yet satisfy the model requirement. The proposed experiment is targeting on direct cross section measurement of the key ${ }^{19} \mathrm{~F}(p, \alpha){ }^{16} \mathrm{O}$ reaction right down to the Gamow energies (70$350 \mathrm{keV}$ in the center-of-mass frame) with a precision better than 10\% (He 2014).

A 'lamp'-type Micron silicon array will be constructed for the charged particle measurement, which can cover about $4 \pi$ solid angle. This universal detection array will set the base for studying the charged-particle-induced reactions at JUNA. It can not only measure the total $\left(p, \alpha_{0}\right)$ cross section but also the angular distribution. The experimental angular distribution is very useful for revealing nuclear structure of the low-energy resonances. In this experiment, a thin target of about $4 \mu \mathrm{g} / \mathrm{cm}^{2} \mathrm{CaF}_{2}$ will be utilized, which is evaporated on a thin metal backings.

The counting rates are deduced from the CJPL-II environment and detector $\gamma$ and neutron measurement data. The results are summarized in Table 1. We also compared our expected precision of data with current experimental results. The results are summarized in Table 2.

\section{Accelerator, shielding system and summary}

We adopted a design of $2.45 \mathrm{GHz}$ ECR which is developed to CI-ADS project. This ion source is expected to deliver $12 \mathrm{emA}$ proton, $6 \mathrm{emA} \mathrm{He}^{+}$and $2.5 \mathrm{emA} \mathrm{He}^{2+}$. The maximum beam energy out of ion source is $50 \mathrm{keV} / \mathrm{q}$ with emittance less than $0.2 \pi \cdot \mathrm{mm} \cdot \mathrm{mrad}$.

For the low energy and high intensity beam, the space-charge effect must be controlled during transmission in order to increase the transport efficiency. The high transport efficiency could not only ensure enough beam intensity on target, but also reduce the background brought by the beam itself. We plan to adopt segmental voltage for the 


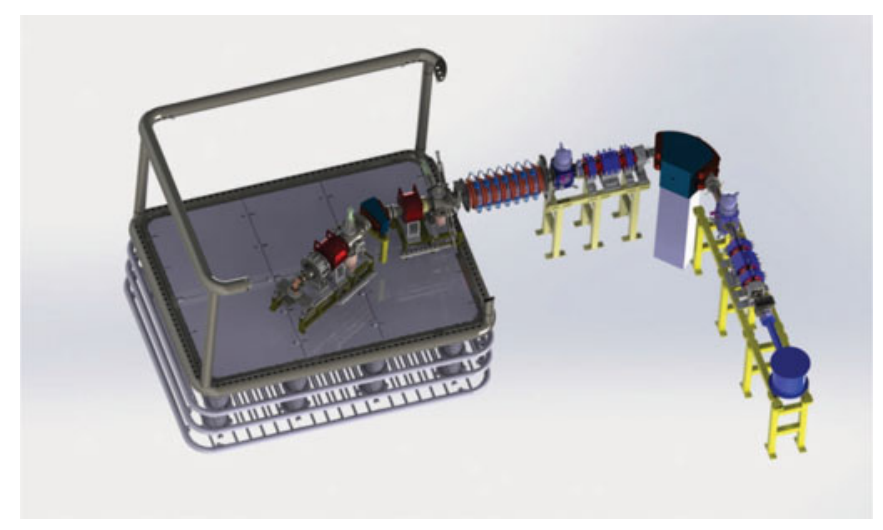

Figure 1. Design of the low energy and high current accelerator system.

accelerating tube and design an acceleration and deceleration structure for the accelerating tube electrode to reduce the space-charge effect.

The effect to background ratio of the nuclear reaction measurement will be significantly enhanced with the ultra-low background of CJPL and high current beam. But at the same time the high current beam will bring new background, which must be shielded. We plan to construct two shielding systems around the target chamber and the detectors, aiming at shielding $\gamma$-ray and neutron, respectively.

In summary, a new underground nuclear astrophysics experiment JUNA is planned for the expanded space CJPL-II. JUNA has the potential to take a favorable position among underground nuclear astrophysics labs. The accelerator system and detector array will be installed in 2017, experiment will be started in 2018 and the first batch of experimental results will be delivered in 2019 .

\section{References}

Rolfs, C. \& Rodney, W. S. 1988, Cauldrons in the Cosmos The University Chicago Press Iliadis, C. 2007, Nuclear Physics of Stars, Wiley-VCH Verlag GmbH

Formicola, A., Imbriani, G., Junker, M, et al. 2003, Nuclear Instruments $E^{3}$ Methods in Physics Research, 507(3):609-616.

Costantini, H., Formicola, A., Imbriani, G., et al. 2009, Reports on Progress in Physics, 972(8):086301.

Chen, H. S. 2010, Science(in Chinese), 62: 4

Cheng, J. P., Wu, S. Y., Yue, Q., et al. 2011, Physics (in Chinese), 03(03):149-154.

Zhao, W., Yue, Q., Kang, K. J., et al. 2013, Physical Review D, 88(5):1201-1205.

Normile, D. 2014, Science, 346(6213):1041-1041.

Buchmann, L. 2005, Nuclear Physics A, 758:335c-362c

Liu, W. P., The ${ }^{12} \mathrm{C}(\alpha, \gamma){ }^{16} \mathrm{O}$ reaction proporsal, 2014, unpublished.

Tang, X. D., The ${ }^{13} \mathrm{C}(\alpha, \mathrm{n}){ }^{16} \mathrm{O}$ reaction proporsal, 2014, unpublished.

Strieder, F., Limata, B., Formicola, A., et al. 2012, Physics Letters B, 707:60-65.

Straniero, O., Imbriani, G., Strieder, F., et al. 2013, Astrophysical Journal, 763(2).

Li, Z. H., Su, J., Li, Y. J., et al. 2015, Science China Physics, Mechanics 63 Astronomy, 58.

He, J. J. 2014, The ${ }^{19} \mathrm{~F}(\mathrm{p}, \gamma){ }^{16} \mathrm{O}$ reaction proporsal, unpublished.

Hammer, J. W., Fey, M., Kunz, R., et al. 2005, Nuclear Physics A, 758:363-366.

Drotleff, H. W., Denker, A., Knee, H., et al. 1993, Astrophysical Journal, 414:735-739.

Lombardo, I., Dell'Aquila, D., Leva, A. D., et al. 2015, Physics Letters B, 2015:178-182. 